\title{
Formação de professores e ensino de Português como Língua Adicional
}

\author{
Juliana Bertucci Barbosa \\ Universidade Federal do Triângulo Mineiro (UFTM), Uberaba, Minas Gerais, Brasil \\ julianabertucci@gmail.com \\ Deolinda de Jesus Freire \\ Universidade Federal do Triângulo Mineiro (UFTM), Uberaba, Minas Gerais, Brasil \\ deofreire@uol.com.br
}

DOI: http://dx.doi.org/10.21165/el.v46i2.1721

\begin{abstract}
Resumo
Este artigo tem como objetivo apresentar o resultado de uma pesquisa com professores/alunos do Mestrado Profissional em Letras (PROFLETRAS) da Universidade Federal do Triângulo Mineiro (UFTM) sobre o ensino de Português como Língua Adicional. Segundo afirmam alguns autores, como Oliveira (2013), o crescimento da língua portuguesa no Brasil e no mundo fez com que os professores de português tivessem de se preparar para o desafio de pensar sua língua materna também como estrangeira e/ou adicional. Para conhecer a atual realidade do ensino da língua portuguesa como adicional na escola pública, iniciamos uma pesquisa com a proposta de mapear os conceitos que os professores têm em sua prática profissional sobre língua nacional, língua padrão, língua materna, língua estrangeira e diversidade linguística no Brasil. A partir desse mapeamento, propomo-nos a discutir sobre o conceito e a importância da língua adicional no ensino do português.
\end{abstract}

Palavras-chave: língua portuguesa; língua adicional; ensino de português.

\section{Formación del profesor y enseñanza del Portugués como Lengua Adicional}

\section{Resumen}

Este artículo tiene como objetivo presentar el resultado de una investigación con profesores/alumnos del Mestrado Profissional em Letras [Maestría Profesional en Letras] (PROFLETRAS) de la Universidade Federal do Triângulo Mineiro (UFTM) sobre la enseñanza del Portugués como Lengua Adicional. Como defienden algunos autores, como Oliveira (2013), el crecimiento de la lengua portuguesa en Brasil y en el mundo hizo que los profesores de portugués se preparasen para el desafío en pensar su lengua materna también como extranjera y/o adicional. Para conocer la realidad actual de la enseñanza del portugués como lengua adicional en la escuela pública, empezamos una investigación con el intento de mapear los conceptos que los profesores tienen en su práctica profesional sobre lengua nacional, lengua estándar, lengua materna, lengua extranjera y diversidad lingüística en Brasil. A partir de ese mapeo, nos proponemos a discutir el concepto y la importancia de la lengua adicional en la enseñanza del portugués.

Palabras-claves: lengua portuguesa; lengua adicional; enseñanza de portugués. 


\section{Introdução}

Um considerável número de pesquisas e publicações sobre o ensino de Português como Língua Estrangeira/Adicional (PLE/PLA) demonstra que essa área tem conquistado cada vez mais espaço dentro da comunidade científica. Esse interesse pode ser comprovado, principalmente, pela ampliação da oferta de cursos de Português como língua estrangeira/adicional e pela implantação do Certificado de Proficiência em Língua Portuguesa para Estrangeiros (Celpe-Bras) - desenvolvido e outorgado pelo Ministério da Educação. Como destaca Oliveira (2013, p. 417), a partir de 2004 houve um crescimento da língua portuguesa no Brasil e no mundo, pois constatamos a ampliação do "letramento da população, a inserção dos países na sociedade internacional, o crescimento da classe média, criando uma produção e um consumo cultural mais sofisticado, mais viagens ao exterior e maior acesso à Internet". Esses fatores contribuíram para que houvesse um interesse maior pelos países de língua portuguesa e, consequentemente, uma maior abertura para seu aprendizado como estrangeira e/ou adicional.

Entretanto, apesar desse crescimento, ainda é escasso o número de instituições de ensino superior, incluindo as universidades públicas, em que há a oferta de cursos de português como língua estrangeira/adicional. Inclusive, não é comum que os cursos de Letras contemplem em suas grades disciplinas que abordem o ensino, bem como a formação de professor, de língua portuguesa como estrangeira e/ou adicional.

Pelo exposto, nosso objetivo é apresentar resultados de uma pesquisa realizada com professores da Educação Básica que são alunos do Mestrado Profissional em Letras (PROFLETRAS) da Universidade Federal do Triângulo Mineiro (UFTM). A necessidade da pesquisa surgiu durante a preparação da bibliografia e do material para a disciplina "Produção de material didático para o ensino de Língua Portuguesa como Adicional". Antes de iniciar as leituras, debates e trabalhos sobre o tema, foram aplicados dois questionários para conhecer os conceitos de língua, dialeto e diversidade linguística no Brasil que os professores da educação básica carregam para sua prática diária. Ademais, os questionários foram pertinentes para que pudéssemos saber sobre a realidade de cada um em sala de aula com relação à presença de alunos estrangeiros ou com alguma deficiência, principalmente a visual e a auditiva.

A partir do desenvolvimento desse trabalho, propomo-nos a refletir, bem como questionar, os posicionamentos teórico-metodológicos sobre a formação de professores em relação ao ensino de língua portuguesa como estrangeira e/ou adicional e sobre o multilinguismo no Brasil. A análise dos resultados dessa pesquisa interessa não apenas à comunidade científica, mas também aos professores da rede básica de ensino. Afinal, apesar de não possuírem um conhecimento aprofundado sobre o tema, esses professores são colocados em situações em que é imprescindível conhecer as concepções teóricas sobre língua adicional, bem como estrangeira. Ademais, é de extrema necessidade que eles conheçam os materiais didáticos disponíveis no mercado para trabalhar com alunos estrangeiros, indígenas e deficientes auditivos ou visuais que tenham a língua portuguesa como estrangeira ou adicional. 


\section{Diversidade Linguística no Brasil}

A homogeneização da língua portuguesa, bem como de seu uso, começa a ser delineada no final do século XVIII com a política do Marquês de Pombal (SILVA, 1995). É relevante lembrar que, nessa época, se inicia, ou melhor, impõe-se uma nova política linguística e cultural no Brasil, envolvendo a primeira rede leiga de ensino e a expulsão dos jesuítas. É a partir dessa época que a língua portuguesa passa a ser obrigatória e o uso de quaisquer outras línguas é proibido.

A eficácia da política pombalina pode ser atestada ainda hoje, principalmente quando professores de português da escola pública afirmam reconhecer a diversidade de sua língua, mas não as 'outras línguas' existentes e em uso no território brasileiro. Os professores, ao serem questionados sobre a diversidade linguística, mencionam as línguas indígenas, no entanto, sentem-se incapazes de reconhecer as distinções entre elas, como se os indígenas e suas línguas pertencessem a um grupo homogeneizado. Rosa Virgínia Matos e Silva, em seu trabalho de 1988, já apontava que, no Brasil, há a convivência de, pelo menos, 170 línguas indígenas. Apesar dessa diversidade, ainda impera a "crença" em boa parte da academia de que se trata de um país monolíngue. Para Silva (1988, p. 17), "o processo quinhentista persiste, a ideologia da homogeneização cultural e linguística também, mudados apenas os senhores".

Silva destaca que ainda encontramos, em trabalhos científicos sobre o português brasileiro, afirmações que atestam a "espantosa unidade" da língua falada no Brasil. Para a linguista, os que professam essa unidade

[...] partem de um confronto entre a dialetação geográfica portuguesa e brasileira. Isso que se pode chamar de julgamento estereotipado, não se fundamenta no conhecimento exaustivo da realidade linguística do Brasil que de resto ainda é insuficiente e fragmentariamente estudada. (SILVA, 1988, p. 25).

As respostas dos professores/alunos que participaram da pesquisa sobre a diversidade linguística no Brasil reiteram a crença de unidade e uniformidade no uso da língua portuguesa e o desconhecimento das especificidades das línguas indígenas. Ademais, as colocações dos professores nos fazem perceber certos julgamentos negativos sobre a presença de palavras estrangeiras no português, como se existisse uma "língua pura". O perigo desse juízo é estender tal crítica ao emprego de termos regionais no uso da língua portuguesa. Segundo Massini-Cagliari (2004, p. 15-16, tradução $\left.\operatorname{nossa}^{1}\right)$ :

É interessante observar que essas duas manifestações de preconceito linguístico (contra um elemento externo e contra um elemento interno supostamente inferior) têm uma origem comum: o mito de que a língua portuguesa no Brasil é caracterizada por uma maravilhosa unidade (Bagno, 2002a: 15) e por uma associação entre o Estado (Nação) e

\footnotetext{
${ }^{1}$ It is even more interesting to observe that these two manifestations of linguistic prejudice (against the external element and against the supposed inferior internal element) have a common origin: the myth that Portuguese language in Brazil is characterised by an amazing unity (Bagno, 2002a: 15) and the association between State (the Nation) and Portuguese as its official language (Silva \& Moura, 2002: 11). On the one hand, the denial of multilingualism and, on the other hand, the exclusion of speech and ways of speaking that are not in strict correspondence with this idealised Portuguese are direct and concrete results of a social posture plenty of linguistic prejudice. (MASSINI-CAGLIARI, 2004, p. 15-16).
} 
o Português como sua língua oficial (Silva \& Moura, 2002: 11). Por um lado, a negação do multilinguismo e, por outro, a exclusão da fala e de modos de falar que não correspondem ao português idealizado são resultados diretos e concretos de uma posição social repleta de preconceito linguístico.

O preconceito linguístico e a negação do multilinguismo dificultam o reconhecimento da diversidade do português, bem como a compreensão de que se trata de uma língua "multicêntrica", afinal dispõe de mais de uma norma. Atualmente, a língua portuguesa tem normas europeias, normas brasileiras e normas africanas, além de outras em processo de criação (CASTILHO, 2013).

Nessa perspectiva, possuem diversidade os países em que se fala mais de uma língua, como o caso do Brasil, em que sobreviveram mais de cem línguas indígenas, além das línguas de imigração, de Moçambique, Angola, Guiné Bissau, Timor-Leste, etc. Como afirma Castilho (2013, p. 11-12), "uma política linguística brasileira articulada deveria tomar em conta essas características de nossa sociedade". O (re)conhecimento dessas línguas contribuiria para que o professor refletisse o ensino do português como língua estrangeira e/ou adicional, afinal, ensiná-lo para um indígena exigiria repensar o seu material didático e sua metodologia.

\section{Língua Adicional e Formação de professores}

Como já mencionado, a área de Português como Língua Adicional ou como Língua Estrangeira (doravante PLA/PLE) muito se desenvolveu nos últimos anos em relação à institucionalização no Brasil e no exterior (BBPORTUGUESE, 2013). Entretanto, o ensino e a aprendizagem de Português como Língua Adicional ou Língua Estrangeira em situação de formação de professores ainda carece de muitas reflexões, pois em muito precisamos avançar. É provável que esses passos lentos decorram da própria constatação de que também é necessário ver a língua portuguesa falada no Brasil como uma língua estrangeira (LEURQUIN, 2013). A dificuldade em abordar o português a partir desse viés deve-se também ao pouco reconhecimento das diversas línguas em uso no Brasil, conforme exposto no tópico anterior.

Cabe mencionar que a palavra "adicional" é o termo mais comumente usado do que "segunda língua" ou "língua estrangeira". Um dos motivos é o fato de os estudantes, algumas vezes, estarem aprendendo não uma segunda, mas uma terceira ou quarta língua. "Adicional" se aplica a todas, exceto, claro, à primeira língua aprendida. Ademais, uma língua adicional pode não ser estrangeira, já que muitas pessoas no seu país podem falar essa língua rotineiramente.

Como exemplo dessa realidade, basta pensarmos na situação dos países africanos de língua portuguesa ou até mesmo na Espanha, em que há, pelo menos, quatro línguas oficiais. O termo "estrangeiro" pode, com efeito, sugerir "estranho", "alheio" ou outras conotações indesejáveis. Nossa escolha pelo termo 'adicional' sublinha o nosso entendimento de que línguas adicionais não são estrangeiras, logo, também não são inferiores ou superiores, nem substitutas para a primeira língua de um estudante (ELLIOT et al., 2001). 


\section{Procedimentos metodológicos}

A partir dos pressupostos teóricos comentados, elaboramos e aplicamos dois questionários no primeiro dia de aula da disciplina "Produção de material didático para o ensino de Língua Portuguesa como Adicional" para subsidiar nossas discussões teóricas e práticas em sala de aula. O objetivo primordial foi diagnosticar os conceitos sobre língua nacional, língua padrão, dialeto e diversidade linguística que os professores da Educação Básica, pós-graduandos do Mestrado Profissional em Letras (PROFLETRAS) de uma universidade pública do Triângulo Mineiro, praticam em sala de aula e/ou trazem de sua trajetória acadêmica.

Além desses conceitos, nossa proposta era também a de conhecer a realidade de cada professor a respeito dos alunos que recebem em sua escola. Para isso, uma das perguntas dos questionários averiguava se o professor já havia tido algum deficiente auditivo ou visual, estrangeiro ou indígena entre seus alunos. Ao final da disciplina, aplicamos um terceiro e último questionário para compreender de que forma a disciplina contribuiu para uma possível revisão das concepções teóricas, bem como práticas de ensino dos professores após os debates e trabalhos realizados ao longo do semestre. Foram participantes da pesquisa quinze (15) professores/mestrandos.

Os dados dos questionários foram analisados de forma quantitativa e qualitativa. Para a análise quantitativa, utilizamos os recursos do Excel, aplicativo Windows, que fornece ferramentas para organizar, analisar e interpretar dados. Das quatro funções principais deste aplicativo, as utilizadas foram "planilhas" (com o uso de fórmulas) e "banco de dados". Após essas tabulações dos dados, realizamos a análise exploratória, selecionando os componentes que nos interessavam relacionados à prática em sala de aula e conceitos linguísticos dos mestrandos do Profletras.

Cabe mencionar ainda que, como o questionário possuía perguntas abertas, também realizamos a análise de conteúdo (MINAYO, 2007) das respostas dos professores, buscando interpretar suas manifestações sobre o nosso objeto de estudo. Segundo Cavalcante et al. (2008), a abordagem qualitativa aplica-se ao estudo da história, das relações, das representações, das crenças, das percepções e das opiniões, produto das interpretações que os indivíduos fazem de como vivem, constroem suas crenças e a si mesmos, sentem e pensam. Assim, neste trabalho, a análise de conteúdo foi utilizada para o aprofundamento de estudos quantitativos.

\section{Análise dos dados}

O primeiro questionário aplicado, como mencionado, referia-se aos conceitos de língua, dialeto e diversidade linguística no Brasil. As respostas sobre língua oficial, nacional e materna mostram que os professores/alunos não conseguem diferenciar $o$ conceito de cada uma delas. A língua oficial, por exemplo, é conceituada como a língua falada "nas escolas" ou "pela maioria da população", ou ainda, a que "é usada nos documentos oficiais". Já a língua materna foi definida como "a mesma língua da família", ou ainda, "a de nascimento" ou "a da alfabetização". 
No que se refere às línguas nacional e oficial, para os respondentes, o conceito de ambas está intrinsecamente relacionado à norma da gramática tradicional, ou seja, refere-se ao uso da norma do plano da idealização, ou seja, da norma padrão (FARACO, 2008). Ademais, os professores defenderam que a 'norma padrão' é aquela ensinada nas escolas. Em nossa análise, essa relação e 'quase' defesa do ensino da norma padrão na sala de aula dificultam pensar e conceber o ensino de Português levando-se em consideração a diversidade linguística e o Português como Língua Estrangeira ou Adicional. Afinal, acaba negando a heterogeneidade linguística presente nas salas de aula, heterogeneidade que deve ser considerada inclusive para ensinar o estrangeiro e o deficiente auditivo ou visual.

Sobre a variação linguística, os professores/alunos afirmam, e acreditam, que ela existe apenas no âmbito familiar e cotidiano. Quando solicitamos, via questionário, para que mencionassem exemplos de variação, os respondentes citaram apenas casos de palavras com variações lexicais e/ou de pronúncia, que geralmente aparecem nos livros didáticos. Esse resultado evidencia que os docentes não conseguem perceber a variação em outros níveis linguísticos, como sintático, semântico e morfológico da língua portuguesa. Por não perceberem a variação em diversos níveis, não consideram aplicar o conceito de variação linguística no ensino de língua, por exemplo, nas aulas de tópicos gramaticais.

Nesse primeiro questionário, preocupamo-nos também em verificar qual o conceito de língua estrangeira para os professores de língua portuguesa, tomando cuidado em não abordar a língua adicional. Afinal, o objetivo era o de verificar se os professores/alunos mencionariam tal termo sem que fosse pedido, no entanto, nenhum dos participantes da pesquisa o mencionou. Com relação ao conceito de língua estrangeira, a maioria respondeu que se trata da "língua de uma pessoa de outro país", ou ainda, a "língua que não se aprende na família".

Quando questionados sobre a diversidade linguística, ou seja, quais línguas são faladas no Brasil, os participantes da pesquisa citaram, de forma geral, línguas indígenas, braile e libras, sem se darem conta de que braile não seria uma língua 'falada'. Dos participantes, apenas três (03) mencionaram línguas estrangeiras, como o chinês e as línguas africanas em geral. A análise dessas respostas evidencia que há certo desconhecimento das línguas faladas no Brasil, a ausência da nomenclatura das línguas indígenas e das estrangeiras, entre elas, a língua de fronteira 'portunhol', pode estar associada à falta de mapeamento e divulgação das línguas faladas no território brasileiro ou à falta de interesse sobre o tema da diversidade linguística em território brasileiro.

O segundo questionário aplicado tinha como objetivo conhecer a prática dos professores em sala de aula quando recebem um aluno estrangeiro ou deficiente, tanto auditivo como visual. Dos quinze (15) professores/alunos, onze (11) já tiveram, em sala de aula, alunos com algum tipo de deficiência - visual ou auditiva - e quatro (04) já tiveram alunos estrangeiros - Paraguai, França, Alemanha e Portugal. Nenhum deles tiveram alunos indígenas em sala de aula.

No que se refere à prática de ensino de língua portuguesa, em suas respostas, os professores afirmaram que quando recebem um aluno que tenha português como língua adicional, normalmente, recorrem a improvisações, pois não se sentem preparados para preparar uma aula de acordo com as necessidades desses alunos. Ademais, a maioria acredita que faltam profissionais e materiais específicos para ajudá-los em tais 
situações. Algo que nos chamou a atenção nas respostas sobre a preparação de materiais didáticos é o fato de os professores não conhecerem o método comunicativo para o ensino de língua estrangeira e/ou adicional.

O último questionário foi aplicado após as aulas, debates, seminários e trabalhos para a disciplina "Produção de material didático para o ensino de Língua Portuguesa como Adicional". O objetivo era o de aferir a contribuição, tanto teórica quanto prática, dos textos e das discussões para a formação do professor/aluno. Dentre os conceitos trabalhados ao longo do semestre sobre língua, dialeto e diversidade linguística, os professores foram indagados sobre qual deles havia sido revisado e/ou atualizado. A maioria afirmou que, de forma geral, os conceitos de língua nacional, oficial, materna e estrangeira foram revisados e que o conceito de língua adicional era quase totalmente desconhecido. Alguns professores afirmaram que "nunca tinha[m] ouvido falar" de língua adicional.

Como consequência desse desconhecimento, noventa por cento (90\%) dos professores responderam que não conheciam o exame Celpe-Bras, e apenas dez por cento (10\%) afirmaram que já "tinham ouvido falar" dessa certificação da língua portuguesa, mas desconheciam a prova e os métodos de aplicação, bem como a correção. Cabe lembrar que Celpe-Bras é o Certificado de Proficiência em Língua Portuguesa para Estrangeiros, desenvolvido e outorgado pelo Ministério da Educação (MEC) do Brasil. Tal exame é aplicado no Brasil e em outros países com o apoio do Ministério das Relações Exteriores (MRE). O Celpe-Bras é o único certificado de proficiência em português como língua estrangeira reconhecido oficialmente pelo governo do Brasil. Além disso, no Brasil, é exigido pelas universidades para ingresso em cursos de graduação e em programas de pós-graduação, bem como para validação de diplomas de profissionais estrangeiros que pretendem trabalhar no país. Algumas entidades de classe exigem o Celpe-Bras para inscrição profissional, como, por exemplo, o Conselho Federal de Medicina (CFM) e os Conselhos Regionais de Medicina (CRM).

Cabe aqui destacar a relevância do professor de língua portuguesa conhecer o exame Celpe-Bras, principalmente pelo fato de ser uma prova que considera a linguagem como uma ação conjunta de participantes com um propósito social, algo que os docentes podem aplicar em suas aulas (SCHLATTER, 1999). Esse exame tem como conceito de "falante proficiente" (partindo das necessidades de uso da língua-alvo) aquele que utiliza a língua de maneira adequada para desempenhar ações no mundo. Por isso, acaba sendo fundamental considerar com quem se pratica a linguagem, em que contexto e com quais objetivos. A visão de linguagem do exame, portanto, é a da língua enquanto comunicação ${ }^{2}$ - conceito que os professores não souberam explicar -, uma atividade social entre falantes que vão interagir, construindo e trocando sentidos, de

\footnotetext{
${ }^{2}$ Scaramucci (1995) define o conceito comunicativo do exame como uso de um código em situações reais de comunicação, sabendo usar a língua em diferentes contextos, adequados às situações socioculturais ou profissionais e a seus interlocutores. O exame Celpe-Bras é aplicado por meio de tarefas que se assemelham a situações de uso na vida real, não aferindo explicitamente conhecimentos sobre a língua através de questões sobre gramática e vocabulário, mas sim a capacidade de uso dessas formas. Nessa perspectiva, a competência comunicativa do candidato é avaliada diretamente através de seu desempenho em tarefas. O fato de não incluir questões sobre gramática e vocabulário não significa que esses elementos não sejam importantes na construção de um texto bem elaborado, seja ele oral ou escrito. Ao contrário, esses fatores são levados em consideração na avaliação do candidato.
} 
acordo com a situação em que se encontram. Por isso, nesse contexto, aprender uma língua envolve também reconhecer a importância desses aspectos, e não apenas o seu componente linguístico.

Nessa perspectiva, não cabe a improvisação de material para alunos que tenham o português como língua adicional, como também foi citado pelos nossos participantes da pesquisa, pois o professor deve preparar material que leve os alunos a interagir em situações reais de comunicação, aplicando (e conhecendo) as regras sociais, situacionais e culturais dessa outra língua (em nosso caso, o português), desenvolvendo suas habilidades de uso da linguagem nas mais diversas situações. Assim, compreendemos que entender a importância do exame Celpe-Bras pode não só auxiliar os professores de língua portuguesa, como também chamar a atenção dos autores de livros/manuais didáticos para uma visão de linguagem atual e para a necessidade de um novo tipo de material que se adéque a essa postura teórico-metodológica.

As discussões propostas pela disciplina, principalmente sobre língua adicional e Celpe-Bras, contribuíram para que os professores/alunos refletissem sobre a importância da língua portuguesa no mundo, além de percebê-la, bem como reconhecê-la, como língua estrangeira e língua adicional. Ademais, os professores perceberam que é necessário acionar o conhecimento que têm da metodologia de ensino de língua estrangeira para preparar o material didático de língua portuguesa quando recebem um aluno estrangeiro ou deficiente. Em nossas discussões e debates, foi produtivo fazer com que o professor/aluno perceba que pensar a Língua Portuguesa como estrangeira e/ou adicional auxilia também a pensar em suas aulas de Português como língua materna. Afinal, o aluno que chega à escola básica, na maioria das vezes, não reconhece a língua ensinada na sala de aula como sua língua materna em razão da intensa variação linguística que impera em nosso país.

Seguindo essas reflexões, Kleiman (1989), quando apresentou os requisitos que o professor de línguas precisa ter, já citava, entre eles, a capacidade para experimentar, avaliar, incrementar, adequar e criar métodos e técnicas, além de ter espírito de renovação e disposição em aceitar novos métodos e técnicas. Além disso, o professor, além de saber como motivar os alunos, na perspectiva teórica, deve adquirir conhecimentos linguísticos, bem como de sociolinguística.

Por fim, dos professores que participaram da disciplina e se propuseram a participar da pesquisa, apenas dez por cento (10\%) considerou as discussões e atividades propostas desnecessárias, pois acreditam que elas não contribuíram com sua formação acadêmica nem com a prática profissional. Esses mesmos professores também afirmaram nunca terem tido alunos estrangeiros ou especiais em sala de aula. Em nossa leitura, essas respostas comprovam, em parte, a certeza, ou a esperança, desses professores de que não irão se deparar com o desafio de pensar o português como língua estrangeira ou adicional, pois nunca terão alunos que exigirão pensar nessa situação.

\section{Considerações finais}

Os resultados preliminares da pesquisa indicam que discutir o ensino da língua portuguesa como língua estrangeira ou adicional contribui para que os professores repensem sua prática e desenvolvam um olhar mais crítico para a diversidade cultural e linguística da sala de aula, bem como a necessidade de adaptar o material didático para 
essa realidade. Para a continuidade da pesquisa, parece-nos pertinente pensar sobre o fato de os professores/alunos não mencionarem a variação linguística, bem como a diversidade, como algo determinante para preparar suas aulas. Ademais, é, no mínimo, curioso que o professor não consiga pensar a língua portuguesa como estrangeira, o que pode comprovar o desprestígio do Português no mundo, tanto na área política quanto econômica.

Como já afirmou Scaramucci (2001,p. 107), que estudou a influência da prova de inglês do vestibular da UNICAMP em escolas de ensino médio:

[...] se o professor não tiver uma formação adequada, alinhada com as tendências contemporâneas, vai ter dificuldades em entender a natureza e as características das inovações propostas, condição fundamental para que venham a ser efetivamente implementadas na preparação dos alunos.

Dessa forma, nosso trabalho evidenciou que os professores ainda não possuem uma formação alinhada com essa visão contemporânea de linguagem, que ofereça condições para que possam entender e trabalhar com a língua levando-se em consideração a diversidade linguística, bem como o português em situação adicional. Por isso, acreditamos que esta pesquisa possa servir de "pontapé" inicial para outras ações que se fazem necessárias na formação do professor de Educação Básica.

\section{REFERÊNCIAS}

BBPORTUGUESE. Translation Services. The Future of Portuguese. Nova Iorque, 2013. Disponível em: <http://www.bbportuguese.com/the-future-ofportuguese.html $>$. Acesso em: 02 mar. 2016.

BRASIL. Certificado de proficiência em língua portuguesa para estrangeiros. Manual do examinando. Brasília: Ministério da Educação, 2015. Disponível em: $<$ http://download.inep.gov.br/outras_acoes/celpe_bras/manual/2012/manual_examinand o_celpebras.pdf $>$. Acesso em: $10 \mathrm{abr}$. 2016.

CASTILHO, A. Desafios para a promoção e a internacionalização da língua portuguesa. Colóquio sobre A internacionalização da língua portuguesa: concepções de ações. Mesa-redonda sobre "A língua portuguesa e suas perspectivas para o século XXI". UFSC, 6 a 8 de março de 2013. Disponível em: $<$ Www.museudalinguaportuguesa.org.br>. Acesso em: 07 mar. 2016.

CAVALCANTE, R. B. et al. Análise de conteúdo: considerações gerais, relações com a pergunta de pesquisa, possibilidades e limitações do método. In: Inf. \& Soc.:Est., v. 24, n. 1, p. 13-18, jan./abr. 2014.

ELLIOT, L. et al. Teaching additional languages. Genebra: International ${ }^{3}$ Academy of Education/International Bureau of Education, 2001.

FARACO, C. A. Norma Culta Brasileira: desatando alguns nós. São Paulo: Parábola Editorial, 2008.

\footnotetext{
${ }^{3}$ International Bureau of Education (IBE) é o instituto da UNESCO especializado em conteúdos, métodos e estruturas educacionais.
} 
KLEIMAN, A. B. Formação do professor: retrospectivas e perspectivas na pesquisa. In: KLEIMAN, A. B. (Org.). A Formação do Professor: perspectiva da Lingüística Aplicada. Campinas: Pontes, 2001. p. 13-25.

LEURQUIN, L. V. L. F. Que dizem os professores sobre o seu agir professoral? In: GERHARDT, A. F. L. (Org.). Ensino-aprendizagem na perspectiva da Linguística Aplicada. São Paulo: Pontes, 2013.

MASSINI-CAGLIARI, G. Language Policy in Brazil: monolingualism and linguistic prejudice. Language Policy. n. 3. Holanda: Kluwer Academic Publishers, 2004. p. 3-23.

SILVA, R. V. M. A sócio-história do Brasil e a heterogeneidade do português brasileiro. ABRALIN, São Paulo, n. 17, p. 73-85, 1995.

Diversidade e unidade: a aventura lingüística do português. Revista ICALP, Lisboa, n. 11, p. 60-72, 1988.

Diversidade e unidade: a aventura lingüística do português ( $2^{\mathrm{a}}$ parte). Revista ICALP, Lisboa, n. 12/13, p. 12-27, 1988.

MINAYO, M. C. S. O Desafio do Conhecimento: Pesquisa Qualitativa em Saúde. 10. ed. São Paulo: HUCITEC, 2007.

OLIVEIRA, G. M. de. Política Linguística e Internacionalização: a língua portuguesa no mundo globalizado do século XXI. Trabalhos de Linguística Aplicada, Campinas, n. 52.2, p. 409-433, jul./dez. 2013.

SCARAMUCCI, M. V. R. O projeto Celpe-Bras no âmbito do Mercosul: contribuições para uma definição de proficiência comunicativa. In: ALMEIDA FILHO, J. C. P. Português para Estrangeiros: interface com o espanhol. Campinas: Pontes, 1995. p. 7790.

SCARAMUCCI, M. V. R. Propostas curriculares e exames vestibulares: potencializando o efeito retroativo benéfico da avaliação no ensino de LE (inglês). Contexturas, São Paulo, n. 5, p. 97-109, 2001.

SCHLATTER, M. Celpe-Bras: Certificado de Língua Portuguesa para estrangeiros breve histórico. In: CUNHA, M. J.; SANTOS, P. (Org.). Ensino e Pesquisa em Português para Estrangeiros. Brasília: Editora UnB, 1999. p. 97-104.

Recebido em: 15/09/2016

Aprovado em: 29/11/2016 